\title{
Restar importancia a la ética en la Formación del Contador Público: Una mala decisión en las universidades ecuatorianas
}

\section{Downplaying Ethics in Public Accountant Training: A Bad Decision in Ecuadorian Universities}

\begin{abstract}
Maribel del Rocío Paredes Cabezas. ${ }^{1}$, Rocío Marisol Guachamboza Moposita. ${ }^{2}$ \& Luis Efraín Velasteguí López. ${ }^{3}$
\end{abstract}

\begin{abstract}
.
DOI: https://doi.org/10.33262/visionariodigital.v4i3.1396

Ethics is an essential element in the human being in any field that develops, either at a personal or professional level, at an individual or collective level. Ethics focuses its attention on the understanding and rational application of principles and values that guide the responsible behavior of the human being. Maintaining ethical behavior generates excellence and credibility in the professional, so this work tries to make a critical analysis of some social contradictions and responsibilities that must be assumed by all social actors. The role of universities in the training of new professionals plays a transcendental role. This article focused its attention on the curricular network offered by the Ecuadorian universities for the formation of the Public Accountant. Ethics in this field as well as in all activities of human activity becomes the fundamental pillar and basis for a development based on trust. This study concentrated the analysis on 15 universities belonging to the RUEE and has a code of institutional ethics, but only 6 of them include ethics in their curriculum as part of the curriculum in the formation of new accountants. Ethics should not be considered only as an indicator, but must seek excellence and credibility in the professional, as its mission will be to ensure collective interests.
\end{abstract}

\footnotetext{
${ }^{1}$ Universidad Técnica de Ambato, Facultad Contabilidad y Auditoría, Ecuador, maribeldparedes@uta.edu.ec

2 Universidad Técnica de Ambato, Facultad Contabilidad y Auditoría, Ecuador, rcguachamboza11@gmail.com

${ }^{3}$ Ciencia Digital, Ecuador, luisefrainvelastegui@cienciadigital.org
} 
Keywords: Ethics, Values, Principles, Public Accountant, Curricular mesh, Professional Competencies.

\section{Resumen.}

La ética constituye un elemento esencial en el ser humano en cualquier ámbito que este desenvuelva, ya sea a nivel personal o profesional, a nivel individual o colectivo. La ética centra su atención en la comprensión y aplicación racional de principios y valores que guían la actuación responsable del ser humano. Mantener una conducta ética genera excelencia y credibilidad en el profesional, por lo que el presente trabajo intenta hacer un análisis crítico de algunas contradicciones y responsabilidades sociales que deben ser asumidas por todos los actores sociales. El papel de las universidades en la formación de nuevos profesionales juega un papel trascendental. Este artículo centró su atención en la malla curricular ofertada por las universidades ecuatorianas para la formación del Contador Público. La ética en este campo al igual que en todas las actividades del quehacer humano se convierte en el pilar fundamental y base para un desarrollo basado en la confianza. Este estudio concentró el análisis en 15 universidades que pertenecientes a la RUEE y cuenta con un código de ética institucional, pero tan solo 6 de ellas incluyen en su malla curricular la ética como parte de la malla curricular en la formación de los nuevos contadores. La ética no debe ser considerada tan solo como un indicador, sino que debe procurar excelencia y credibilidad en el profesional, pues su misión será velar por los intereses colectivos.

Palabras claves: Ética, Valores, Principios, Contador Público, Malla curricular, Competencias Profesionales.

\section{Introducción.}

La ética de acuerdo a estudios de Varó (2008) y Castillo (2012) constituye un elemento esencial en el ser humano y centra su atención en la búsqueda de una comprensión racional de los principios y valores que otorgan validez a la conducta responsable del ser humano, es decir rige sobre el comportamiento moral de las personas desde un enfoque racional y crítico.

El comportamiento ético de los empresarios y de los profesionales que colaboran al interior de las organizaciones revela la identidad de las mismas. En este contexto se espera que el cumplimiento de las tareas a ellos encomendadas sea ejecutado de manera eficiente, responsable, bajo principios y valores. Mantener una conducta ética genera excelencia y credibilidad en el profesional, pues su misión será velar por los intereses colectivos.

La ética forma parte integral de la sociedad en general, por lo que el presente trabajo intenta hacer un análisis crítico de algunas contradicciones y responsabilidades sociales que deben 
ser asumidas por todos los actores sociales. Es evidente que en este contexto el papel de las universidades en la formación de nuevos profesionales juega un papel trascendental.

Este artículo centrará su análisis en la malla curricular ofertada por las universidades ecuatorianas para la formación de profesionales en el área contable. La ética en este campo al igual que en todas las actividades del quehacer humano se convierte en el pilar fundamental y base para un desarrollo basado en la confianza. La ética consiste la práctica constante de valores, los mismos que se convierten en un medio para poder alcanzar un fin, manteniendo una relación íntima con la moral y la conducta del ser humano.

Este estudio propone como idea central para el debate y análisis el hecho de que en 6 de las 15 universidades que pertenecen a la Red Universitaria de Ética del Ecuador (RUEE), en su malla curricular no han considerado incluir o han eliminado a la ética dentro de la formación del contador público y que paradójicamente cuenta con un código de ética institucional, que intenta fortalecer "un proceso académico honesto y transparente", mediante "declaraciones de principios y valores, fundamentos morales y éticos de carácter universal, dentro de la vida universitaria", es decir que este código de ética "establece pautas de conducta que deben respetarse (...) por parte de todos quienes forman la Comunidad Universitaria en sus acciones diarias". (Código de Ética UTA, 2015)

El disponer de un código de ética al interior de las universidades en el Ecuador surge a partir del Modelo de Evaluación Institucional de Universidades y Escuelas Politécnicas publicado en marzo del 2015, por el Consejo de Evaluación, Acreditación y Aseguramiento de la Calidad de la Educación Superior (CEAACES) que menciona a la ética como un indicador de recategorización de las Instituciones de Educación Superior (IES).

La ética no debe ser considerada solo por cumplir con un indicador, sino al igual que la opinión de Küng en el trabajo de González (2012) la ética no debe ser tratada como "un documento conceptual o de una vaga declaración de buenas intenciones, sino de un conjunto de prescripciones basadas en valores morales compartidos por todas las culturas y sancionados por la práctica a lo largo de siglos".

\section{Objetivos.}

- Enfatizar la influencia de la ética profesional como eje transversal en la formación del Contador Público en las universidades ecuatorianas, para su desempeño eficiente en el campo laboral, capaz de enfrentar con honestidad los retos de la sociedad actual.

- Analizar la importancia de combinar los conocimientos técnicos y científicos con valores y principios éticos, a fin de que el profesional contable se interrelacione de una manera correcta con las diversas ideologías empresariales sin faltar a su conducta moral 
desempeñando con éxito las exigencias del demandante moderno mundo de los negocios, la banca y las finanzas.

- Plantear una matriz que vincule la integración de competencias de orden técnico y científico con el fomento de valores y principios éticos, como pilares fundamentales de una formación sólida y de calidad del profesional contable en la educación superior ecuatoriana.

\section{Marco Teórico.}

La ética es un conjunto de hábitos o costumbres producto no solo del acuerdo social, sino de una revisión crítica basado en la estricta aplicación de normas, valores y principios morales concretos para orientar la conducta de los individuos en la vida cotidiana. González (2012) agrega que es necesario contar "con valores y una ética compartidos para el funcionamiento adecuado del entramado económico, político y social, y por tanto, para el bienestar y el desarrollo de todas las posibilidades de cada ciudadano del mundo”.

Y es precisamente el entorno económico quien más exige de la participación honesta de los profesionales con formación en administración, economía, finanzas, contabilidad y auditoría. Suárez \& Contreras (2012) resalta el papel de la academia en la formación de contadores públicos con verdadero sentido de responsabilidad social profesional, en donde "el contador juega un papel importante en la toma de decisiones de los entes económicos y cuenta con amplia confianza social y normativa".

El mundo en el que vivimos está cambiando de forma acelerada, por impulso del avance tecnológico y de la globalización. La velocidad, la profundidad y la escala de los cambios a los que se ven sujetos los ciudadanos actualmente ponen en serio cuestionamiento el comportamiento ético de los profesionales tanto a nivel de organizaciones públicas como privadas.

Luego de leer los artículos publicados por García (2006) Gómez y Domínguez (2015) Sanromán, González y Villa (2015) sobre "Ética en las Profesiones”, "Los valores éticos en la Responsabilidad Social Corporativa", "Principios Ético y Obligaciones Civiles" fue posible identificar tres campos de la ética que van desde la ética aplicada, meta ética, ética normativa.

Tabla 1. Campos de la Ética

\begin{tabular}{|c|c|c|}
\hline Campo & Comprende & Ejemplos \\
\hline Ética Aplicada & $\begin{array}{l}\text { Estudia cuestiones morales y } \\
\text { controversiales que pueden } \\
\text { surgir en cualquier campo }\end{array}$ & $\begin{array}{c}\text { Ética médica, ética profesional, } \\
\text { ética en los negocios, etc. }\end{array}$ \\
\hline
\end{tabular}




\begin{tabular}{cll}
\hline & Es la justificación de los & \\
Metaética & principios y como deben actuar & Ética social, Ética y \\
los integrantes de una sociedad, & responsabilidad social \\
& establece lo que es juicio y moral & \\
& Principios del deber y las normas & \\
& morales, conjunto de buenos & \\
Ética Normativa & comportamiento virtudes. Conducta y & Ética personal \\
& respecto a las reglas planteadas o & \\
& necesarias para la convivencia o & \\
& desarrollo & \\
\hline
\end{tabular}

Fuente: Elaboración propia.

Además, en un estudio presentado por Resaee (2012) sobre Gobierno Corporativo y Ética Empresarial sugiere que la ética puesta en práctica al interior de las organizaciones es un código de conducta bien establecido y que si se logra aplicarlo de manera efectiva proporcionará estándares éticos y pautas sobre la resolución de conflictos de intereses, obliga a mantener la confidencialidad de la información, a fin de promover el comportamiento ético y el cumplimiento de las leyes y normas aplicables entre sus ejecutivos

\section{Ética en la formación del contador público}

El contador público de acuerdo con Woolf y Hindson (2015) es el encargado de dar credibilidad a los estados financieros, por lo que deberá tomar todas las medidas razonables y necesarias para garantizar su actuación responsable y honesta, a nivel personal y de la firma que representa frente a terceros. No importa si la empresa es grande o pequeña, es importante emitir una carta de compromiso que defina la naturaleza y el alcance específico del asesoramiento del profesional contable, asesoramiento que tiene que estar delimitado por principios éticos.

Maida \& Pérez (2011) consideran que "en la actualidad, la carrera de Contador es una de las principales profesiones que los estudiantes eligen" a su ingreso a las universidades y esperan recibir durante su formación una serie de conocimientos que le permitan ejercer su profesión de una manera eficiente, el contador debe ser capaz de afrontar distintas situaciones en las cuales habrá que tomar decisiones en forma oportuna y adecuada.

La ética juega entonces un papel trascendental en su formación, pues una vez requerido en el ámbito profesional, esté debe alcanzar una comprensión plena del medio en el que se va a desenvolver, permitiendo el contacto con la realidad y sean capaces de establecer relaciones sociales sin desvirtuar la importancia de manejar principios y valores. 
Vol. 4, N³, p. 224-246, julio-septiembre, 2020

Gráfico 1. Ética como eje central de la actuación del ser humano como ser social

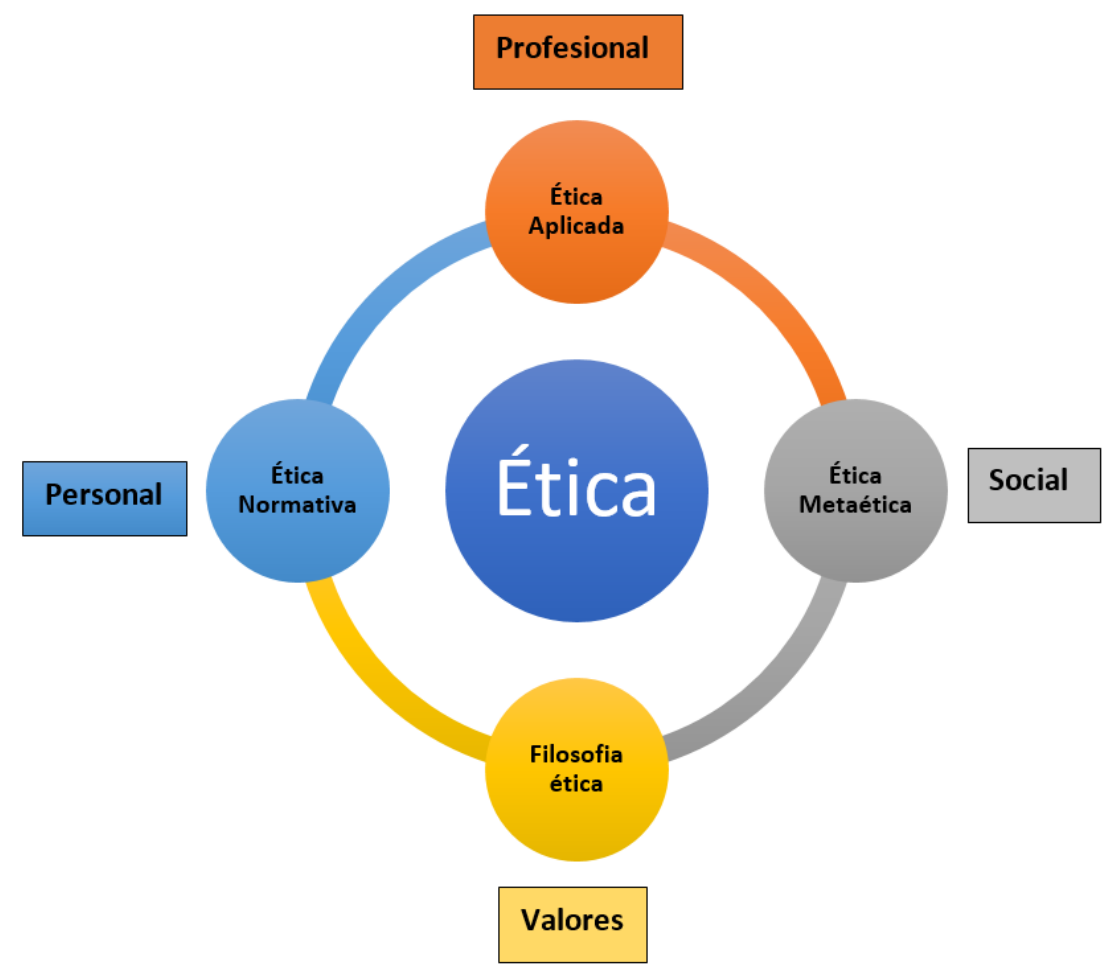

Fuente: Elaboración propia.

Surge entonces la ética profesional, así según Vigo (2014) consiste en mantener firme la responsabilidad que tiene un ser humano como actor en la sociedad y desde su campo de acción intentar ser un buen y verdadero profesional capaz de mantener sus valores y principios.

Si a esto le añadimos el sentido real que tiene ejercer una profesión, pues esta va más allá de una simple ocupación o desempeño. La profesión le permite a un ciudadano obtener ingresos e incluso un nivel de vida aceptable. Por lo que en la realidad la profesión es una práctica social que adquiere verdadero sentido cuando se profesión es puesta al servicio de la sociedad. Por lo que se espera que todo profesional oriente su comportamiento basado en directrices que le permitan cumplir con una serie de valores éticos en favor de la sociedad y no sirviendo únicamente a intereses particulares (Cortina, 2007).

\section{El papel de las universidades en la formación de profesionales.}

En los últimos años de acuerdo con Vargas, Cruz, Gatica \& García (2015) la imagen del Contador Público está perdiendo credibilidad debido principalmente a escándalos financieros 
con la colusión de un profesional contable en el ejercicio de su profesión como Contador o peor aún como Auditor.

Vargas, Cruz, Gatica \& García en el 2015 desarrollaron una investigación sobre el rol del "Contador Público como líder del cambio social en el nuevo escenario educativo mexicano" en este estudio ellos enfocaron su análisis desde la perspectiva de la responsabilidad social como un aporte de la academia a las organizaciones para que ellas puedan conducir sus actuaciones desde este nuevo enfoque en favor de la sociedad. Además "describen de forma general la función social de la universidad mexicana y de manera especifica en el ámbito del contador público, valorando la exigencia y pertinencia de actuar como líder del cambio social que demanda su entorno" (pág. 234) por supuesto enmarcado dentro de parámetros y principios éticos y de responsabilidad social.

La tarea principal de las universidades es formar profesionales competentes, se requiere por tanto de manera urgente impulsar una educación de calidad, es decir que la academia deberá formar a los nuevos profesionales con un valor agregado que les permita un desempeño eficiente y correcto dentro de la sociedad Paredes., Cruz., \& Velastegui (2018, pág. 223) "para lo cual será necesaria la participación de todos los actores involucrados (...) y la confluencia de distintos factores, tales como: contenidos adaptados al entorno y realidades locales"

En este contexto conviene citar uno de los objetivos del Plan Decenal de Educación del Ecuador (2016) el mismo que plantea "Educar integralmente para el desarrollo personal y la equidad social”. En el mismo sentido Wong \& Salcedo (2014, pág. 70) consideran que las universidades no deben descuidar su posición formativa pues al hacerlo corren el riesgo de perder su identidad. No pueden dedicar sus esfuerzos exclusivamente a "atender sólo la eficiencia pragmática, funcional o administrativa, solamente con fines utilitarios, un sistema educativo sin respuesta es solo un sistema". Wong \& Salcedo agregan además que no "es lo mismo educar e instruir (...) no basta ser instruido; hay que ser mejor persona, ser ético."

Las universidades sin duda alguna juegan un papel fundamental pues deben ser capaces de entregar profesionales probos al servicio de la sociedad, por lo que deben diseñar modelos educativos de calidad que potencien la educación superior al nivel de las exigencias de un mundo cada vez más cambiante.

Solo entonces las IES podrán garantizar que la inclusión de nuevos profesionales en el mercado laboral se trata de seres humanos integrales, que no solo dominan los conocimientos técnicos y científicos inherentes a su profesión, sino que al ponerlos en práctica lo harán bajo una conducta moral intachable, basados en sólidos principios morales y éticos. 
Figura 1: Factores que deben impulsar las universidades para formar profesionales competentes.

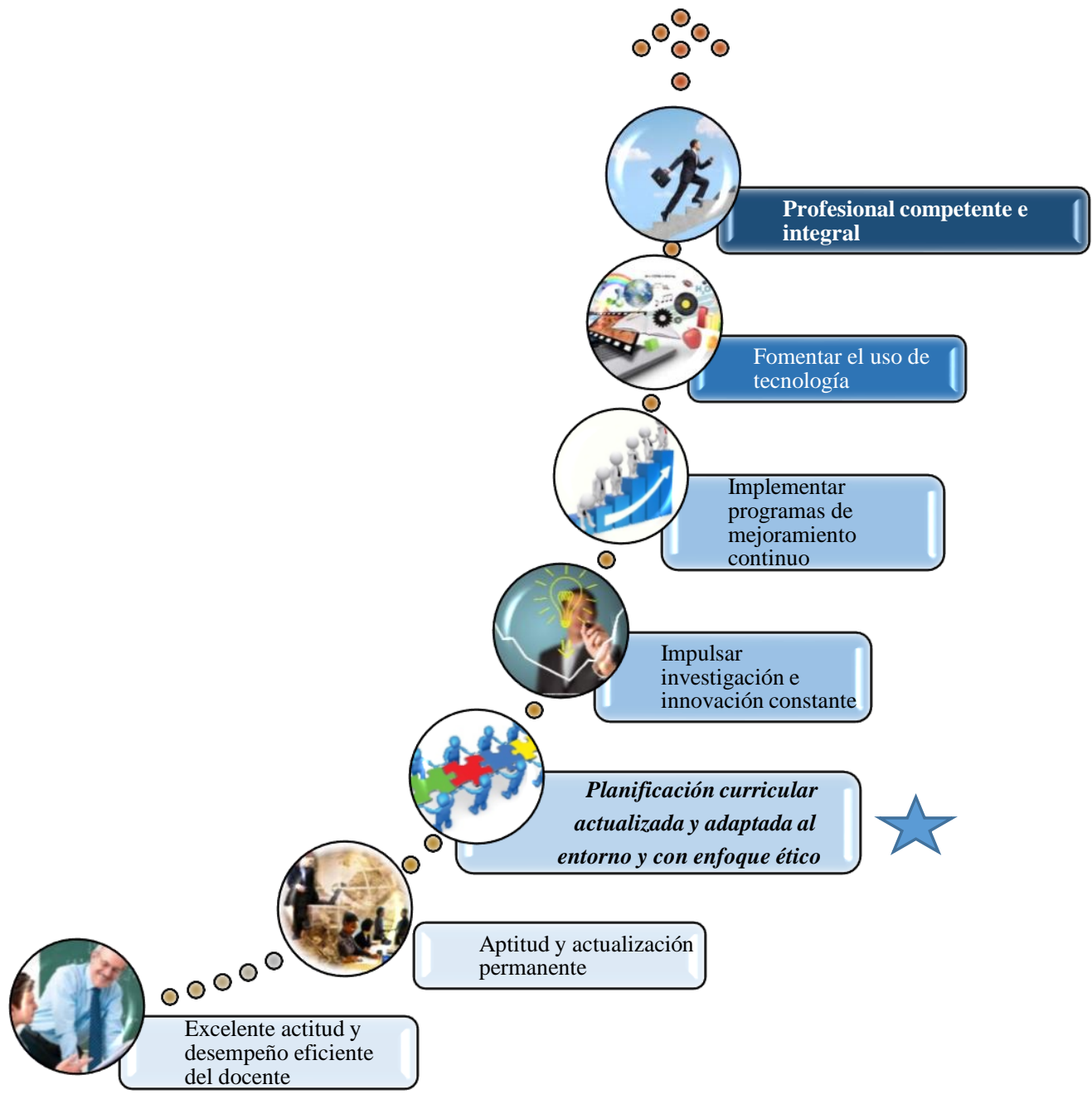

Fuente: Elaboración propia.

\section{Ética dentro de las mallas curriculares.}

El mundo moderno de los negocios, así como la globalización y la internalización de la economía, obliga las organizaciones y a los profesionales en general a reinventarse constantemente si desea ser competitivos. El Contador Público no es la excepción por el contrario resulta ser una "pieza clave en el ámbito de la contabilidad, las finanzas y la administración”. Por lo que cada vez tiene una participación mayor en la toma de decisiones.

La imagen del Contador debe ser intachable, con una conducta moral basada en sólidos principios éticos "con habilidad profesional, formación integral, capacidad de liderazgo y responsabilidad social”' (Vargas, Cruz, Gatica, \& García, 2015). 
Es así que el perfil de egreso de los nuevos profesionales es una labor complicada que está confiada principalmente a los directivos de las universidades, debido a que la profesión de contabilidad es muy sensible en cualquier ámbito. Deben por lo tanto enfocarse en formar profesionales que cumplan las expectativas de la sociedad. Los constantes cambios, la velocidad de las relaciones económicas, tecnológicas, requieren del desarrollo de capacidades, habilidades y aptitudes que permita adaptarse al contexto formando profesionales responsables, capaces de enfrentarse a su entorno.

La enseñanza de la ética está ligada principalmente con la educación moral, con los valores, el respeto hacia los demás, las universidades lejos de eliminar de sus mallas la ética, debería incluirla no solo como una asignatura aislada, sino como eje transversal para la formación integral del profesional contable.

Si bien la ética, los valores y principios vienen de la casa, es tarea del sistema educativo fomentarlo a lo largo del proceso enseñanza aprendizaje, es decir que esta tarea empezada en los hogares debe ser complementada en la escuela primaria, a nivel secundario y por supuesto se debe consolidar a nivel universitario, por lo que como ya se dijo no basta solo con una asignatura dentro de las instituciones educativas. Bajo este argumento Lara, Pérez, \& Barriga, (2018) manifiestan que la ética "constituye una de las finalidades de la educación universitaria", por esta razón "no puede quedar en segundo plano ni desarticulada de la formación referida a los saberes y métodos propios de las disciplinas". Por lo que en la malla curricular deben estar inmersos varios temas relacionados con la ética para formar profesionales con responsabilidad social.

Osorio (2010) resalta la necesidad de contar con una formación integral que contemple al menos estos cuatro escenarios "humanístico, científico, tecnológico e innovador" con miras a la formación social y productiva que promueva la ampliación del conocimiento técnico científico al campo humanístico, es decir con enfoque ético, social y responsable.

Resulta entonces de vital importancia que la formación del Contador Público al igual que la de todos los profesionales esté orientada a mantener en ellos una firme convicción de sus principios, para ejercer la profesión de una manera correcta, al mismo tiempo buscando el beneficio de la sociedad desarrollando su trabajo con responsabilidad.

Es evidente entonces que las universidades tienen la responsabilidad de formar profesionales como ciudadanos comprometidos con la sociedad para brindar servicios lícitos. Las universidades Colby (2003) citado por Bolívar (2005, pág. 104) “deben promover el desarrollo de las capacidades de los estudiantes para examinar situaciones complejas en que compiten varios valores". En este contexto las universidades están en la obligación de 
formar profesionales con pensamiento lógico, capaz de resolver problemas y emitir juicios de valor.

\section{Dilemas que aparecen por ausencia de ética en un profesional contable.}

Restar importancia de la ética dentro de las universidades, resulta ser una mala decisión en las universidades ecuatorianas. Dedicarse a formar profesionales con sólidos conocimientos científico - técnicos no es suficiente, pues su tarea es muy delicada y la universidad no puede darse el lujo de formar profesionales con carencia de valores, no puede solo enfocarse a la formación práctica, debe también evidenciar su papel en la formación de seres comprometidos con la responsabilidad social que está en sus manos, debe evidenciar su papel protagónico en la formación con sentido humanístico y ético.

En la actualidad el Ecuador se ha visto envuelto en varios casos de corrupción con repercusiones serias y grandes pérdidas económicas, De acuerdo con el diario El Universo (2018) "la gran tarea que debemos emprender los ecuatorianos es cambiar esta cultura de la "sapada criolla" y que los más honestos tengamos una decidida participación en la vida pública", el articulista de este diario con circulación a nivel nacional enfatiza el hecho de los buenos somos más y que no podemos ni debemos caer en propuestas que arruinen la integridad.

González (2013, pág. 208) presentó un estudio sobre "La ética profesional, su desarrollo en valores en estudiantes de administración y contabilidad", y consideró la necesidad de impartir a la ética dentro de las cátedras universitarias, a fin de que el egresado se convierta en un profesional con capacidad suficiente y criterio moral para "diferenciar entre la información contable y su posición ética ante el uso de dicha información".

La pérdida de valores también es un problema considerado actualmente por el Ministerio de Educación Ecuatoriano por lo que precisamente en este año 2019 se planteó como metas hacer cambios en el ámbito de la educación. Cambios enfocados principalmente "a formar estudiantes más integros", para promover en los estudiantes el respeto hacia los demás, convirtiéndoles en personas con más sensibilidad. De esto modo busca este organismo cambiar a la sociedad y evitar no solo fraudes a nivel escolar como es el "plagio", sino prevenir la participación en actos ilícitos que a futuro pueden generar actos delincuenciales con graves consecuencias a nivel local, regional o estatal.

Varios escándalos han sido protagonizados por el mal uso de la información financiera ya sea a nivel empresarial, a nivel de empresas y organismos estatales e incluso a nivel de los gobiernos de turno. Información que, al no haber sido sigilosamente cuidada, despertó la ambición de varios funcionarios inescrupulosos quienes tomaron ventaja de dicha información, así en Ecuador destaca la crisis financiera que empezó con la "sucretarización" 
de la deuda externa 1983, un feriado bancario en 1999 y que concluyó con la "dolarización" del país en el año 2000.

En el Ecuador desde la sucretización de la deuda externa de la banca privada se generó la idea de que la administración por parte del Estado ecuatoriano era inestable y desatándose el "boom" de las ventas de las empresas estatales que en ese momento eran las más rentables del país a precios irrisorios que no cubría el valor real de las mismas, creando una nueva crisis esta vez con la participación de la banca, lo cual terminó con un feriado bancario, en el cual se apoderaron de los recursos de los ecuatorianos. Todo esto fue una labor muy bien organizada por los políticos que gobernaban al país y la colusión de financistas, contadores y economistas, que en ese momento se encontraban ejercicio su profesión al servicio de una banca y gobierno corruptos.

A partir del feriado bancario decretado en Ecuador en 1999 nuestro país enfrentó una grave crisis económica y de gobernabilidad, que impacto en sociedad lo que originó desempleo, migración de la población, alarmantes cifras de suicidios, elevada cartera vencida a nivel del sistema financiero, altas tasas de interés, etc. El poder ejecutivo tuvo en sus manos la suerte de todo un país, la moneda nacional que era el sucre se encontraba en caída libre, situación generada por un galopante índice de inflación y aguda inestabilidad monetaria, lo que terminó con la muerte de la moneda nacional y adopción del dólar como moneda de curso legal.

El 9 de enero del 2000 Ecuador bajo la responsabilidad histórica del ex presidente Jamil Mahuad dictó sentencia de muerte al sucre. Decisión que según analistas económicos y políticos fue tomada "más por un interés político inmediato que por razones de estrategia o política de Estado" Diario el (Clarín, 9/09/2009) la cual generó gran inestabilidad del país".

La instauración del nuevo modelo económico neoliberal actuó como un gran detonante a favor de los gobiernos y funcionarios corruptos.

Ganando la potestad absoluta de actuar a su favor, beneficiarse de información privilegiada, afectando de manera directa al pueblo ecuatoriano. La economía ecuatoriana se dolarizó, favoreciendo de manera directa a los morosos pues por medio de la dolarización sus deudas se redujeron de manera favorable para ellos, mientras que para los que menos tenían afectación fue realmente significativa, los sueldos se redujeron beneficiando a los banqueros corruptos (Larrea, 2004).

Pero la historia de saqueo del país no acaba ahí, el reciente caso de Odebrecht y su mafia de corrupción a nivel de Latino América, de acuerdo al informe del diario El Universo (2018) es uno de los casos de corrupción más sonados con la colusión directa Carlos Polit ex Contralor de la nación quien de acuerdo a la Constitución de la República del Ecuador en sus Arts. 211 y 212 era el "encargado del control de la utilización de los recursos estatales, 
y de las personas jurídicas de derecho privado que dispongan de recursos público (...) dirigir el sistema de control administrativo" a través de auditoría internas, auditoría externas y permanente control interno.

La situación se agrava aún más cuando en estos actos ilícitos Polit involucra la participación directa de su hijo John Polit, de acuerdo "a la acusación fiscal, Carlos Pólit, siendo Contralor General del Estado, solicitó \$10.1 millones a Odebrecht para el desvanecimiento de glosas que estaban relacionadas al proyecto San Francisco, y por entregar informes favorables de Contraloría para la constructora brasileña respecto a cinco proyectos en los que participaba en Ecuador". afectando de manera significativa a la economía de un país que confiaba en él, de igual manera "a Pólit hijo, Pérez lo acusa de cómplice, pues habría colocado \$1.7 millones en las empresas Cosani, de Panamá, y Plastiquim, de Ecuador. Aparentemente simulaba entregar créditos de la empresa Venture Overseas, cuando ese dinero habría sido parte de lo conseguido a través de coimas transferidas por Klienfeld, offshore de Odebrech". (El Universo, 6/06/2018)

La corrupción reina como un problema cultural, social y a gran escala debido a la falta de valores a nivel personal, familiar y profesional, poniendo en riesgo la credibilidad de profesionales, con el único fin de conseguir poder y estabilidad económica.

El rescate de los valores es una tarea que alguien debe asumirla con responsabilidad, la universidad considerada como el templo del saber debe por lo tanto encargarse de promover en sus egresados el respeto a la sociedad y así prevenir la participación en actos delincuenciales con graves consecuencias a nivel nacional e internacional.

\section{Metodología.}

El desarrollo del presente artículo se basa en diferentes fuentes de tipo documental relacionadas con la formación ética del profesional contable, enfocándose en el análisis y el estudio de las universidades ecuatorianas, con la finalidad de resaltar la influencia de la ética en la formación del Contador Público y su interrelación con diversas ideologías sin faltar a su conducta moral.

Además se realizó entrevistas a directivos y docentes de varias universidades ecuatorianas, así como altos funcionarios de organismos de control como el Servicio rentas Internas Ecuatoriano (SRI) y la Contraloría General del Estado del Ecuador, Superintendencia Nacional de Administración Tributaria de Perú (SUNAT), por lo que el presente estudio se sirvió de un análisis cualitativo con los datos recogidos de dichas entrevistas que evidenciaron algunos aspectos importantes tales importancia significativa de la ética como eje fundamental en el desarrollo formativo de contadores que sean capaces de dar fe pública de sus actos y de las organizaciones que representan. 


\section{Resultados.}

Los resultados obtenidos en esta investigación por un lado evidencian la falta de buenas prácticas profesionales, la falta de responsabilidad social, la crisis de valores y principios éticos que envuelven a la sociedad en una telaraña de escándalos y corrupción que van desde fraudes hasta delincuencia organizada y asociación ilícita.

Es lamentable enterarnos a través de los distintos noticieros a nivel nacional e internacional que en América Latina durante los últimos años cada día salen a relucir un sinnúmero de casos de corrupción. Ilícitos en los que actúan no solo funcionarios de alta jerarquía, sino también mandos medios. Además, el sector privado también sirve de cómplice y en muchos casos de corruptor. En este escenario contadores asumen un "protagonismo" inescrupuloso poniendo sus conocimientos "al servicio de la delincuencia". (Trucco, Cano, Fajardo, \& Vargas, 2016).

Es innegable que la sociedad actual está sumergida la profunda crisis de valores, al parecer la ética ha perdido vigencia, pero eso no debe ser así es hora de que las universidades retomen su papel protagónico y forme profesionales dignos de una sociedad que confía en la actuación ética de todos los profesionales más aún del contador quien da fe de lo actuado financieramente en cualquier entidad sea esta pública o privada. Por su parte Pillaca (2014) considera que el contador debe mantener un comportamiento pues está llamado a mantener sus principios y valores como representante de una sociedad a la que debe su actuación.

En Ecuador varios casos de corrupción han salido a luz como el caso de ex vicepresidente de la República Jorge Glas y su tío Ricardo Rivera fueron condenados a cumplir prisión, por el delito de asociación ilícita y lavado de activos, en complicidad con la constructora brasileña Odebrecht. (Vistazo, 07/12/2017). El caso Arroz Verde donde descubrieron donaciones millonarias, para financiar la campaña en el 2012 de Jorge Glass y Rafael Correa (La República, 01/06/2019). El caso Capaya de acuerdo a la República (2019) destaca que Carlos Pareja Yannuzzelli y su familia fueron condenados a prisión por "la trama de corrupción en Petroecuador". La exvicepresidenta María Alejadra Vicuña acaba de ser declara culpable el 30 de enero del 2020 en el caso Diezmos, por el delito de concusión, conforme lo señaló el Tribunal Penal de la Corte Nacional. Como cereza del pastel está también el caso de Carlos Polit ex contralor de la nación quien se le acusa de emitir informes favorables, pese a las irregularidades detectadas en el proyecto hidroeléctrico San Francisco causando graves perjuicios económicos al país. (El Universo, 6/06/2018).

Pero eso no es todo incluso en medio de la emergencia sanitaria que estamos viviendo a nivel mundial, funcionarios inescrupulosos del IESS (Instituto ecuatoriano de Seguridad Social del Ecuador) pretendieron comprar mascarillas e insumos médicos a precios exagerados que superaban el $\mathbf{5 0 0 \%}$ si al quinientos por ciento sobre el valor comercial. Solo por poner un 
ejemplo una mascarilla $\mathbf{N 9 5}$ que se la consigue en el mercado nacional con precio de venta al público en $\$ \mathbf{2 , 3 5}$ incluso hasta $\$ \mathbf{3 , 9 0}$ pretendieron adquirir a $\mathbf{\$ 1 2 , 0 0}$ a empresas fantasmas o de papel. Lo cual ha derivado en la "destitución del director del IESS, Miguel Ángel Loja, por haber dado paso a la contratación de las mascarillas". (EL TELÉGRAFO 3/04/2020)

Negociaciones millonarias que pretenden continuar saqueando la economía de un país que reclaman justicia, y que antes de la pandemia mundial ya estaba afectado no queremos ni imaginarnos que puede pasar con la economía de esta nación, ahora que las fábricas se encuentran cerradas y trabajando solo un tercio de la población para atender aspectos básicos como son: salud, salubridad, sistema financiero, seguridad ciudadana y seguridad alimentaria. La educación también es un sector que no se ha detenido y gracias a la tecnología ha podido continuar con el proceso enseñanza aprendizaje. Por ello hoy más que nunca recobra importancia el compromiso de las universidades para con la sociedad, quienes debemos formar ciudadanos y profesionales íntegros con sólidos valores y principios.

La ética en este contexto nunca debió haber quedado de lado en las mallas curriculares de ninguna profesión, peor aún de la formación del contador público. Sin lugar a duda como dice el título de este artículo restar importancia a la ética en la formación del contador público es una mala decisión de las universidades ecuatorianas.

La sociedad ecuatoriana se siente muy afectada por todo lo que está viviendo. El sistema de salud está colapsado al 4 de abril se contabilizaron 3.465 contagiados y 172 fallecidos por COVID-19 de acuerdo con datos del último informe presentado por el Servicio Nacional de Riesgos. La pregunta que todos nos hacemos es ¿Qué va a pasar cuando haya más infectados? ¿Qué va a pasar cuando haya más muertos? Seguro hoy toda la sociedad está saboreando una amarga y triste realidad, sienten que si los fondos públicos, hubieran sido custodiados en forma responsable y bajo un compromiso ético por parte sobre todo del Contralor de la nación (Contador de la nación, Auditor de la nación como Uds. quieran llamarlo no deja ser un profesional responsable de las finanzas públicas) que se supone cuidaba del buen uso del erario fiscal y que además se esperaba responda al pueblo y no a interés personales o a intereses políticos. Que dejan a la deriva la suerte del pueblo ecuatoriano.

El desvío de los fondos públicos restringe el acceso servicios como: educación, transporte, agua, alcantarillado, energía eléctrica, seguridad, salubridad y salud, estos últimos tan necesarios y prioritarios durante la emergencia sanitaria. El mundo entero quedo absortó con la construcción de hospitales en China en cuestión de días, varios seguramente fueron los factores que permitieron que la construcción de los hospitales fuera una realidad; pero sobre todo gracias a la disponibilidad de fondos públicos, pues sin los recursos necesarios nada es posible. 
Vol. 4, N³, p. 224-246, julio-septiembre, 2020

Todo lo anteriormente señalado destaca la importancia de la ética en la formación del contador y la responsabilidad que tienen las universidades de formar ciudadanos con criterio ético, por lo que a continuación se presenta un resumen de 15 universidades que pertenecen a RUEE y que contando con un código de ética institucional no necesariamente han puesto el mismo interés en la malla curricular para la formación del Contador Público.

Tabla 2. Universidades que pertenecen a RUEE

\begin{tabular}{|c|c|c|}
\hline No.1 & \multicolumn{2}{|c|}{$\begin{array}{c}\text { UNIVERSIDADES QUE PERTENECEN A } \\
\text { RUEE }\end{array}$} \\
\hline 1 & & Escuela Politécnica del Litoral \\
\hline 2 & & Escuela Politécnica Nacional \\
\hline 3 & & $\begin{array}{c}\text { Pontificia Universidad Católica del } \\
\text { Ecuador }\end{array}$ \\
\hline 4 & & Universidad Central del Ecuador \\
\hline 5 & & Universidad de Especialidades Turísticas \\
\hline 6 & & $\begin{array}{c}\text { Universidad de las Fuerzas Armadas } \\
\text { ESPE }\end{array}$ \\
\hline 7 & y & Universidad de Otavalo \\
\hline 8 & $=$ & Universidad del Pacífico \\
\hline 9 & msilu & Universidad Laica Eloy Alfaro de Manab \\
\hline 10 & & $\begin{array}{c}\text { Universidad Laica Vicente Rocafuerte de } \\
\text { Guayaquil }\end{array}$ \\
\hline 11 & & Universidad Metropolitana \\
\hline 12 & 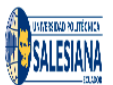 & Universidad Politécnica Salesiana \\
\hline 13 & & Universidad San Gregorio de Portoviejo \\
\hline 14 & & Universidad Técnica de Ambato \\
\hline 15 & & Universidad Tecnológica Equinoccial \\
\hline
\end{tabular}

Fuente: Elaboración propia. 
Tabla 3. Universidades de RUEE que cuentan con carreras en Contaduría Pública

\begin{tabular}{|c|c|c|c|}
\hline $\mathbf{N}^{\mathbf{o}}$ & UNIVERSIDADES & Nombre de la asignatura & Semestre \\
\hline 1 & 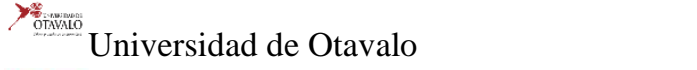 & Ética y formación profesional & Sexto \\
\hline 2 & 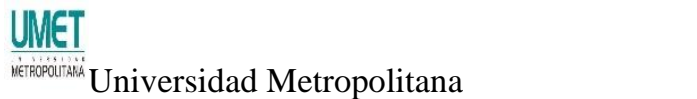 & Ética profesional & Primero \\
\hline 3 & Iniversidad de las Fuerzas Armadas ESPE & \multicolumn{2}{|c|}{ No tiene dentro de su malla la ética } \\
\hline 4 & Universidad Tecnológica Equinoccial & \multicolumn{2}{|c|}{ No tiene dentro de su malla la ética } \\
\hline 5 & Universidad Laica Eloy Alfaro de Manabí & Ética y responsabilidad social & Séptimo \\
\hline 6 & Und & Ética & Séptimo \\
\hline 7 & Universidad del Pacífico & Ética & Décimo \\
\hline 8 & iversidad Central del Ecuador & \multicolumn{2}{|c|}{ No tiene dentro de su malla la ética } \\
\hline 9 & Universidad San Gregorio de Portoviejo & $* * *$ & $* * *$ \\
\hline 10 & (0) Universidad Técnica de Ambato & \multicolumn{2}{|c|}{ No tiene dentro de su malla la ética } \\
\hline
\end{tabular}

Fuente: Elaboración propia.

Gráfico 2. Representación de universidades de la RUEE que mantienen una asignatura de ética en la malla curricular para la formación del Contador Público

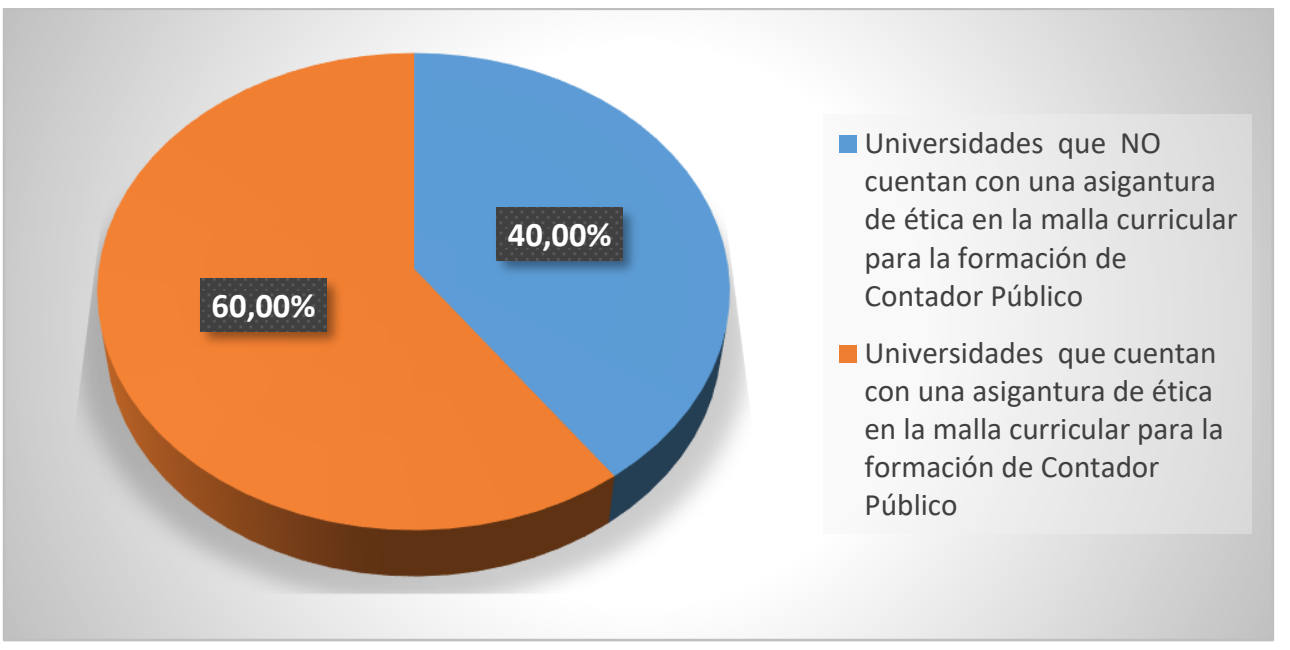

Fuente: Elaboración propia. 


\section{Propuesta.}

García (2006) señala que sociólogos e historiadores han estado siempre preocupado de investigar sobre la ética profesional como un fenómeno social. Cita trabajos previos de Herbert Spencer, Max Weber, Emilio Durkheim, Hortal, los cuales permiten concluir que la ética profesional conduce una vida moral en el ejercicio profesional, es decir mantener una congruencia entre lo que se "dice y hace”. Por lo que las universidades deben procurar que en la práctica profesional esto se cumplido como una regla básica de comportamiento ético.

Figura 2. Propuesta de contenidos mínimos de ética en la Malla Curricular del Contador Público

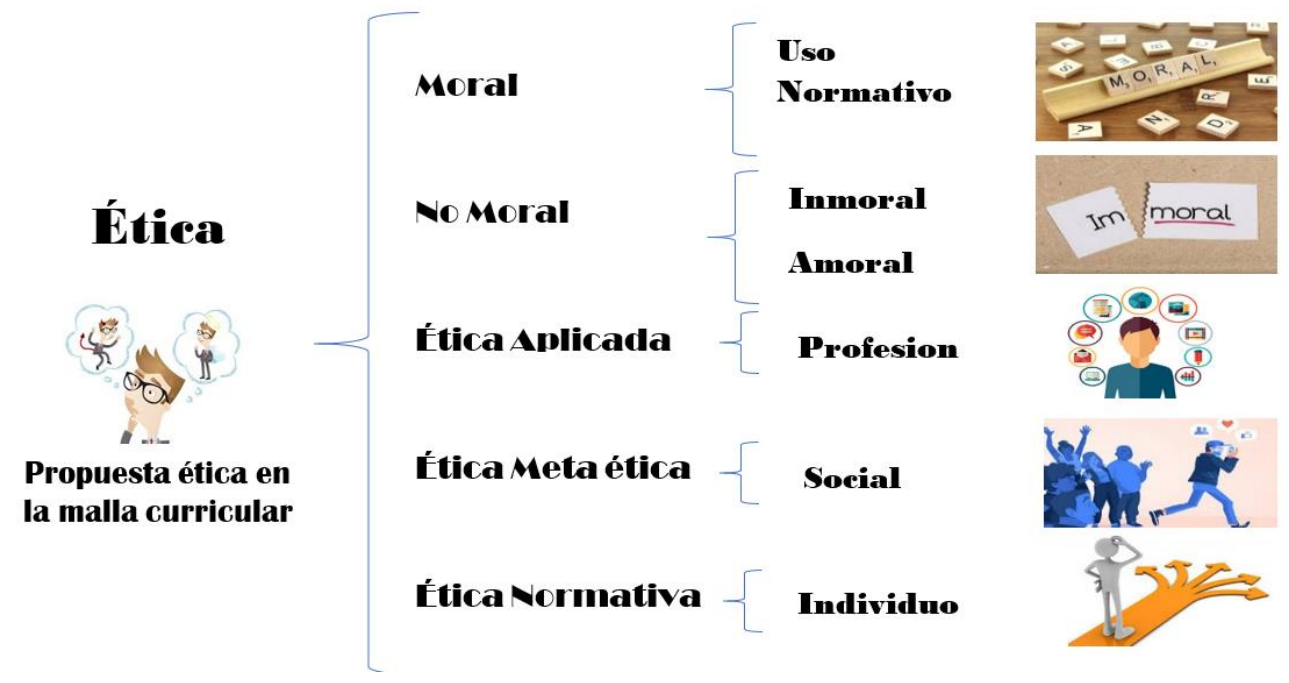

Fuente: Elaboración propia.

Deben entonces en las universidades tomar en serio su papel protagónico de formar profesionales integrales y bajo la denominación que fuera (Ética y Formación Profesional, Ética y Responsabilidad Social, Ética y Valores, Ética en los Negocios, Código de Ética Comercial, Código de conducta y Buenas Prácticas bajo la ley federal, etc.), incluir en la malla curricular como eje transversal temas relacionados con principios éticos, que fueron inculcados en la familia, afianzados durante la educación básica, reforzados en el bachillerato y reafirmados en la educación superior, solo entonces se estará garantizando su correcta aplicación en el ámbito profesional.

\section{Conclusiones.}

- Por tanto, la formación de profesionales en un mundo globalizado y crisis permanente de valores plantea un serio desafío al sistema de educación superior, quien es el llamado a actuar con prontitud y en forma proactiva ante tan lamentable situación. 
- Las universidades ejercen sobre la sociedad pueden provocar efectos positivos en el desarrollo de una sociedad ya sea en el orden económico, social, ambiental y/o culturales por lo que precisamente las universidades están obligadas entregar la sociedad profesional probos, íntegros capaces de atender las demandas y necesidades en un mundo globalizado y competitivo y dónde él decide mantener una congruencia entre lo que "dice y lo que hace".

- El sistema educativo a nivel superior requiere de políticas orientadas a potenciar la formación científico-técnica de los Contadores Públicos, así como afirmación permanente de buenas prácticas bajo estrictos principios y valores éticos no negociables a las exigencias e intereses de unos pocos, sino amparadas en la responsabilidad social y bienestar de la sociedad. Por lo que sin duda alguna se requiere de un amplio apoyo social y político.

- Independientemente del comportamiento de políticos y funcionarios corruptos, las universidades tienen que analizar su rol como protagonista del cambio en la sociedad, no debe limitarse a proporcionar conocimientos científicos y técnicos, debe entregar a la sociedad profesionales competentes con habilidades y destrezas, con calidad profesional y moral reflejada en su ejercicio profesional.

- Si bien la mayoría de las universidades objeto del presente estudio en su misión declaran que la formación de profesionales es dotarlos de "sólidos valores morales y éticos" y por supuesto "con amplios conocimientos técnicos y científicos" esto no ha sido posible evidenciar en el análisis de su malla. Si bien no se niega el hecho de que, en cada una de las cátedras en la universidad, los maestros con conciencia social resaltarán el uso de buenas prácticas profesionales. La ética como tal no se encuentra integrada en la malla ofertada en el $40 \%$ de las universidades objeto.

- Las universidades no deben olvidar que la ética y los valores instituidos en el niño en sus hogares requieren del refuerzo constante, durante la etapa.

\section{Referencias bibliográficas.}

Castillo, R. (2012). Ética del desarrollo. Recuperado el 15 de Abril de 2019, de http://www.eumed.net/cursos/rcb-ed/2.htm

Paredes, Cruz, \& Velasteguí. (2018). Investigación e innovación como valor agregado para una educación superior de calidad. Revista Ciencia digital, 2(2). Recuperado el 26 de Junio de 2019, de http://www.cienciadigital.org/revistascienciadigital/index.php/CienciaDigital/article /view/84

Alatrista, M. (Abril de 2011). Ética profesional. Recuperado el 15 de Abril de 2019, de http://www.reocities.com/miguelalatrista/ETICAPROFESIONAL.htm 
Bolívar, A. (Enero-Marzo de 2005). El lugar de la ética profesional en la formación universitaria. Revista Mexicana de Investigación Educativa, 10(24), 32. Recuperado el 29 de Abril de 2019

CEAACES. (2015). Modelo de Evaluación integral de Universidades. Recuperado el 25 de Junio de 2019, de https://www.ucsg.edu.ec/wpcontent/uploads/transparencia/Modelo-evaluacion-preliminar-universidadesescuelas-politecnicas2018.pdf

Código de Ética UTA. (2015). Universidad Técnica de Ambato consejo directivo. Recuperado el Junio26 de 2019, de https://www.uta.edu.ec/v3.2/uta/reglamentosinternos/codigoetica.pdf

Constitución de la República del Ecuador. (2008). Constitución de la República del Ecuador. Recuperado el 29 de Junio de 2019, de https://www.oas.org/juridico/mla/sp/ecu/sp_ecu-int-text-const.pdf

Cortina, A. (2007). Ética y valores profesionales. Revista Reencuentro(49), 9. Recuperado el 16 de Octubre de 2017, de http://www.redalyc.org/articulo.oa?id=34004907

Diario el Clarín. (09 de Septimebre de 2009). Crisis económica y financiera, Ecuador decretó la muerte del sucre y dolarizó su economía. Recuperado el 29 de Junio de 2019, de https://www.clarin.com/ediciones-anteriores/ecuador-decreto-muertesucre-dolarizo-economia_0_rJ6Yxcx0Fl.html

El Telégrafo. (19 de Junio de 2019). Capaya asegura que la corrupción petrolera partió desde Correa. Recuperado el 29 de Junio de 2019, de https://www.eltelegrafo.com.ec/noticias/politica/3/capaya-corrupcion-petroleragobierno-rafaelcorrea

El Universo. (06 de Junio de 2018). Carlos Pólit y su hijo John Pólit, condenados a seis y tres años de cárcel por concusión en caso Odebrecht. Recuperado el 27 de Junio de 2019, de https://www.eluniverso.com/noticias/2018/06/06/nota/6796388/carlospolit-su-hijo-john-polit-condenados-seis-tres-anos-carcel

El Universo. (5 de Mayo de 2018). La ética, gran tarea para los ecuatorianos. Recuperado el 14 de Junio de 2019, de https://www.eluniverso.com/opinion/2018/05/05/nota/6744317/etica-grantareapara-ecuatorianos

Escuela Politécnica Nacional. (2018). La EPN es miembro fundador de la red de universitaria de ética del Ecuador. Recuperado el 26 de Junio de 2019, de https://www.epn.edu.ec/la-epn-es-miembro-fundador-de-la-red-universitaria-deetica-del-ecuador/ 
Funcionarios IESS destituidos. (3 de 04 de 2020). El Telégrafo.

García, C. (Enero-Marzo de 2006). Ética de las profesiones. Revista de la Educación Superior, $X X X V(1)(137), 7$. Recuperado el 29 de Junio de 2019, de http://www.redalyc.org/pdf/604/60413710.pdf

Gómez, B., \& Domínguez, R. (15 de Agosto de 2015). Los valores éticos en la responsabilidad social corporativa. Revista Universidad de Medellín, 14(28). Recuperado el 29 de Junio de 2019, de https://www.redalyc.org/jatsRepo/4915/491550445001/html/index.html

González, F. (2012). Ética en la empresa y en las Finanzas (BBVA ed.). España. Recuperado el 15 de Abril de 2019

González, I. (20 de Noviembre de 2013). La ética profesional, su desarrollo en valores en estudiantes de administración y contabilidad. Revista Visión Contable(11), 21. Recuperado el 10 de Noviembre de 2017

La República. (10 de Abril de 2019). CAPAYA enfrenta nueva instrucción fiscal por caso Petroecuador. Recuperado el 28 de Junio de 2019, de https://www.larepublica.ec/blog/politica/2019/04/10/capaya-enfrenta-nuevainstruccion-fiscal-por-caso-petroecuador/

Lara, Pérez, \& Barriga. (2018). Para enseñar ética profesional no basta con una asignatura. Revista iberoamericana de educación superior, 7(18), 10. Recuperado el 14 de Junio de 2019, de http://www.scielo.org.mx/scielo.php?script=sci_arttext\&pid=S200728722016000100042

Larrea, C. (2004). Dolarización, Crisis y Pobreza en el Ecuador. Recuperado el 27 de Junio de 2019, de https://www.fesecuador.org/fileadmin/user_upload/pdf/078\%20DOLPOB2004_0418.pdf

Maida, A., \& Pérez, G. (Noviembre de 2011). La formación del criterio profesional del Contador y su importancia en el campo laboral. Recuperado el 27 de Abril de 2019, de http://bdigital.uncu.edu.ar/objetos_digitales/5296/maidalaformacindelcriterioprofesional.pdf

Marqués, G. (08 de Agosto de 2011). Calidad e innovación educativa en los centros Departamento de Pedagogía Aplicada, Facultad de Educación. Recuperado el 27 de Junio de 2019, de http://peremarques.pangea.org/calida2.htm

Mnisteiro de Eduación. (26 de Enero de 2019). Ministerio de Educación realiza cambios en la Malla curricular 2019. Recuperado el 14 de Junio de 2019, de 
https://educarplus.com/2019/01/ministerio-de-educacion-realiza-cambios-en-lamalla-curricular-2019.html

Osorio Valencia, J. (10 de Junio de 2010). Formación integral para la aprobación social del conocimiento. 7(1), 16. Recuperado el 8 de Mayo de 2019

Pamela Martínez declara e involucra a Rafael Correa y a Jorge Glas. (1 de 6 de 2019). La República.

Pillaca, U. (2014). La ética en el desarrollo profesional contable frente al fenómeno de la globalización. Recuperado el 21 de Junio de 2019, de http://revistasinvestigacion.unmsm.edu.pe/index.php/quipu/article/view/5580/4841

Plan Decenal de Educación. (2016). Popuesta de la comunidad educativa como insumo para el nuevo plan decenal de educación. Recuperado el 29 de Junio de 2019, de https://educacion.gob.ec/wp-content/uploads/downloads/2016/03/PLANDECENAL-PROPUESTA.pdf

Resaee, Z. (2012). Corporate Governance and Business Ethics. En Z. Rezaee. Recuperado el 29 de Junio de 2019, de https://onlinelibrary.wiley.com/doi/pdf/10.1002/9781119201335.ch12\#accessDenial Layout

Sanromán, R., Gonzáles, I., \& Villa, M. (Enero-Abril de 2015). Los principios éticos y obligaciones civiles. Revista Boletín Méxicano de Derecho Comparado, XLVIII(142). doi:http://www.redalyc.org/articulo.oa?id=42737102009

Suárez Henao, A. V., \& Contreras Patiño, I. V. (Noviembre de 2012). La formación integral del contador público colombiano desde la expectativa internacional. Revista Gestión y Desarrollo, 12. Recuperado el 08 de Mayo de 2019, de https://www.usbcali.edu.co/sites/default/files/011_contadorpublico.pdf

Tinant, E. (2013). Ética normativa. Éticas del deber y del carácter. Recuperado el 29 de Junio de 2019

Trucco, Cano, Fajardo, \& Vargas. (1 de Noviembre de 2016). La corrupción en Latinoamérica y el ejercicio de la Profesión Contable. Revista FACCEA, 6(2), 7. Recuperado el 20 de Junio de 2019, de https://www.udla.edu.co/revistas/index.php/faccea/article/view/591/607

Vargas, R., Cruz, E., Gatica, L., \& García, P. (Julio de 2015). El Contador Público como líder del cambio social en el nuevo escenario educativo mexicano. Revista Iberoamericana de Ciencias, 11. Recuperado el 26 de Junio de 2019, de http://www.reibci.org/publicados/2015/julio/0700115.pdf 
Varó, À. (2008). ¿Qué es la Ética? Recuperado el 15 de Abril de 2019, de https://www.nodo50.org/filosofem/IMG/pdf/etica1c.pdf

Vigo, R. L. (2014). Ética profesional: especificidad, importancia y. Revista Biblioteca Digital de la Universidad Católica Argentina, 17. Recuperado el 17 de Abril de 2017, de http://bibliotecadigital.uca.edu.ar/repositorio/revistas/etica-profesionalespecificidad-vigo.pdf

Wong, Z., \& Salcedo, L. (10 de Enero de 2014). Retos del contador en la actualidad. Revistas de investigacion UNMSM, 6. Recuperado el 26 de Junio de 2019

Woolf, \& Hindson . (2015). La ética en las empresas. Recuperado el 25 de Junio de 2019

Vistazo. (17 de Diciembre de 2017). Fiscalía pide pena máxima para Glas y Rivera. Recuperado el 30 de Junio de 2019, de https://www.vistazo.com/seccion/pais/actualidad-nacional/fiscalia-pide-penamaxima-para-glas-y-rivera

La República. (1 de Junio de 2019). Pamela Martínez declara e involucra a Rafael Correa y a Jorge Glas. Recuperado el 30 de Junio de 2019, de https://www.larepublica.ec/blog/politica/2019/06/01/pamela-martinez-declarainvolucra-rafael-correa-jorge-glas/ 
PARA CITAR EL ARTÍCULO INDEXADO.

Paredes Cabezas, M. del R., Guachamboza Moposita, R. M., \& Velasteguí López, L. E. (2020). Restar importancia a la ética en la Formación del Contador Público: Una mala decisión en las universidades ecuatorianas. Visionario Digital, 4(3), 224-246. https://doi.org/10.33262/visionariodigital.v4i3.1396

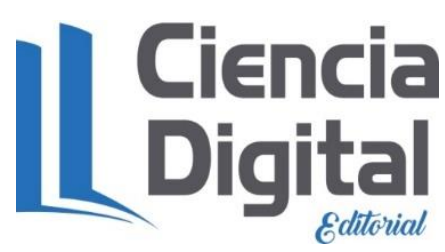

El artículo que se publica es de exclusiva responsabilidad de los autores y no necesariamente reflejan el pensamiento de la Revista Visionario Digital.

El artículo queda en propiedad de la revista y, por tanto, su publicación parcial y/o total en otro medio tiene que ser autorizado por el director de la Revista Visionario Digital.
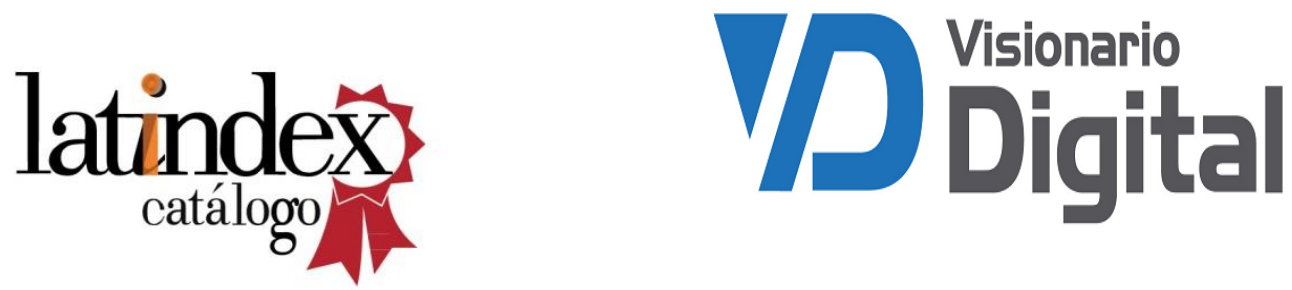